Article

\title{
Ultra-Low Friction on Tetrahedral Amorphous Diamond-Like Carbon (ta-C) Lubricated with Ethylene Glycol
}

\author{
Svenja Bachmann ${ }^{1}$, Marcus Schulze ${ }^{1,2}$, Lisa Krell $^{3}$, Rolf Merz ${ }^{4}$, Michael Wahl ${ }^{4}$ \\ and Robert W. Stark 1,2,* (i) \\ 1 Physics of Surfaces, Institute of Materials Science, Technische Universität Darmstadt, Alarich-Weiss-Str. 16, \\ D-64287 Darmstadt, Germany; Svenja.Bachmann@gmx.de (S.B.); schulze@pos.tu-darmstadt.de (M.S.) \\ 2 Center of Smart Interfaces, Technische Universität Darmstadt, Alarich-Weiss-Str. 10, \\ D-64287 Darmstadt, Germany \\ 3 BMW Group, D-80788 Munich, Germany; Lisa.Krell@bmw.de \\ 4 Institute for Surface and Thin Film Analysis (IFOS), Trippstadter Straße 120, D-67663 Kaiserslautern, \\ Germany; merz@ifos.uni-kl.de (R.M.); wahl@ifos.uni-kl.de (M.W.) \\ * Correspondence: stark@pos.tu-darmstadt.de
}

Received: 23 May 2018; Accepted: 3 July 2018; Published: 7 July 2018

\begin{abstract}
Lubricated tetrahedral amorphous carbon coatings can show a very complex tribological behavior. In particular, friction regimes with extremely low friction have been observed. In tribological experiments with a ta-C/steel friction pair that was lubricated with ethylene glycol, we observed a sudden and very strong decrease in the effective friction coefficient from 0.45 to 0.01 after running-in. By varying different components of the tribological system after this abrupt decrease we investigated the role of the counter-body, the lubricant and the coating. To investigate the surface chemistry, static time-of-flight secondary ion mass spectrometry (ToF-SIMS), dynamic secondary ion mass spectrometry (SIMS), and X-ray photoelectron spectroscopy (XPS) measurements were performed. Using deuterated lubricants, ToF-SIMS measurements allowed us to distinguish adsorption of hydrogen and hydroxyl-groups from the lubricant from the adsorption from the environment. Deuterated hydroxyl-groups from the lubricant adsorbed to the surface during the experiment. In particular, more adsorbed deuterated hydroxyl-groups were detected prior to the sudden decrease in the friction coefficient. Thus, the sudden decrease in the coefficient of friction was most likely caused by an interplay between the lubricant, the ta-C coating and the counter-body which lead to the formation of transfer and adsorption layers.
\end{abstract}

Keywords: diamond-like carbon; ToF-SIMS; XPS; coefficient of friction; ethane-1,2-diol; ta-C

\section{Introduction}

To increase energy efficiency in automotive applications, coatings with low friction and good wear properties are crucial to reduce the energy loss in the drivetrain. In particular, diamond-like carbon (DLC) coatings are relevant candidates to improve the fuel economy owing to their excellent mechanical properties, such as high elastic modulus, high hardness, and low friction and wear. Amorphous carbon coatings are currently widely used in injection pumps, sliding bearings, piston rings, and tappet to name a few examples [1,2]. Further applications include biomedical applications, electrochemistry, or data storage [3-6].

The mechanical and tribological properties of DLC strongly depend on the ratio of $\mathrm{sp}^{3}$ to $\mathrm{sp}^{2}$ carbon bonds and the film composition [4]. To adjust the properties, the coatings can be, for example, doped with metals or non-metals [7]. In addition, hydrogen-free tetrahedral amorphous carbon 
coatings (ta-C) are gaining attention because of the availability of industrial physical vapor deposition technology [8]. The $\mathrm{sp}^{3}$ to $\mathrm{sp}^{2}$ carbon bond ratio of ta-C is higher than in hydrogenated amorphous carbon coatings (a-C:H), which also leads to a higher hardness of ta-C. One particular advantage of ta-C coatings over a-C:H coatings is their better performance when lubricated with MoDTC-containing lubricants because hydrogenated DLC coatings show high wear [9]. Surface chemical analysis using (time-of-flight) secondary ion mass spectrometry (ToF-SIMS) and X-ray photoelectron spectroscopy (XPS) measurements helps to elucidate the tribochemistry of DLC coatings. For example, the creation of graphite-like patches on the coatings could be established for $\mathrm{taC} / \mathrm{taC}$ tribocontacts by means of XPS [10]. SIMS allowed for the detection of lubricant-fragments [11-18], although the detected fragments have not yet been correlated with the different friction levels. Very low friction regimes can be associated with the formation of a transfer layer. Erdemir et al. [19] intensively analyzed the formation of transfer-layers on counter-bodies running dry against DLC. In addition, other authors mentioned the formation of transfer-layers on metallic counter-bodies which are known to prevent further wear of the counter-body, in particular on a-C:H [1].

To exploit the full potential of ta-C, the lubricants need to be tailored to the application. For example, it was observed that friction can be reduced by using polyglycols as lubricants in DLC coated systems [20]. Additionally, the lubrication mechanisms of glycerol on ta-C coatings have been studied extensively over the last years. In this system, the adsorption of the hydroxyl-groups on the surface and the low van der Waals interaction between the hydroxylated surface and the molecules of the lubricant lead to very small friction coefficients.

In the following, we report on the performance of a ta-C coating in a ta-C/100Cr6-steel friction pair which was lubricated with ethylene glycol. Oscillating tribological experiments in ball-on-disc geometry showed an abrupt decrease of the friction coefficient after a long running-in period of nearly $2 \mathrm{~h}$ at elevated temperatures. To investigate the origin of the sudden decrease to an ultra-low friction regime and to better understand the role of the system components, we performed experiments changing the lubricant, the counter-body, and the coating position and investigated the surfaces with respect to changes in surface roughness, wear, and potential adsorbates. Our data suggest that the formation of a transfer-layer on the counter-body is relevant to the reduction in the friction coefficient.

\section{Materials and Methods}

\subsection{Preparation of ta-C Coatings}

The 3- $\mu \mathrm{m}$ thick ta-C coatings were deposited on polished 100Cr6 steel substrates (62 HRC) after the deposition of a chrome adhesion layer. The adhesion layer was deposited in a DC-sputtering process and the ta-C coating by means of laser-controlled pulsed arc technology (Laser-Arc) at a deposition temperature below $100{ }^{\circ} \mathrm{C}$ (Scheibe et al. [21]). Additionally, plasma filtering was used, which reduces the roughness because fewer droplets reach the sample during deposition. The ta-C coatings were lapped after deposition to further reduce their surface roughness.

\subsection{Tribological Characterization}

Prior to the tribological characterization, the coatings were cleaned with acetone and isopropanol in an ultrasonic bath. The tribological properties of the coatings lubricated by ethylene glycol were studied with a ball-on-disc apparatus (SRV 5 test system, Optimol Instruments, Munich, Germany). A load of $50 \mathrm{~N}$ was applied and the experimental temperature was $100^{\circ} \mathrm{C}$. One milliliter of ethylene glycol (Merck KGaA, Darmstadt, Germany, purity $\geq 99.5 \%$ ) was applied as lubricant (density at $20{ }^{\circ} \mathrm{C}$ : $1.11 \mathrm{~g} / \mathrm{cm}^{3}$, viscosity at $60{ }^{\circ} \mathrm{C}: 5.0 \mathrm{cP}, 100{ }^{\circ} \mathrm{C}: 2.0 \mathrm{cP}$, note that ethylene glycol is highly hygroscopic). Pristine 100Cr6-steel-balls with a diameter of $10 \mathrm{~mm}$ were used as a counter-body. The oscillation was achieved by a linear drive with a frequency of $50 \mathrm{~Hz}$ and a stroke of $1 \mathrm{~mm}$. All the tribological experiments were performed at ambient room conditions and repeated at least twice. 


\subsection{Surface Characterization}

The wear behavior was analyzed using an optical microscope and a scanning electron microscope. We analyzed the roughness in the wear track with a confocal microscope (NanoFocus, Oberhausen, Germany) with a cut-off filter at $250 \mu \mathrm{m}$ (low-pass filtered in order to suppress long-wave parts attributed to waviness components).

Atomic force microscopy (AFM) was applied to study roughness and dry friction. An Icon atomic force microscope (Bruker, Billerica, MA, USA) was employed for recording $2 \times 2 \mu \mathrm{m}^{2}$ images using PPP-ZEIHR cantilevers (Nanosensors, Neuchâtel, Switzerland) in the intermittent contact mode at a scanning velocity of $2 \mu \mathrm{m} / \mathrm{s}$. The roughness was evaluated on the full area of the image $\left(4 \mu \mathrm{m}^{2}\right)$, as well as on a sub region of $1 \mu \mathrm{m}^{2}$ that was considered as nearly free of impurities. The AFM lateral force images were used for the calculation of the friction coefficients without lubrication and had a size of $2 \times 2 \mu \mathrm{m}^{2}$. These were taken with a ContDLC cantilever (Budgetsensors, Sofia, Bulgaria) in the lateral force microscopy mode (LFM) at a scanning velocity of $8 \mu \mathrm{m} / \mathrm{s}$. The inverse optical lever sensitivity was obtained from a force-versus-distance curve on sapphire and the flexural force constant was estimated through the thermal noise method. The lateral force was calibrated with a TGF11 calibration grid (Mikromasch, Sofia, Bulgaria) using the wedge calibration method [22]. As a quantitative measure for the friction, the lateral force was plotted versus the normal force $(10-50 \mathrm{nN})$ and the slope of a linear fit was calculated (linear regression).

Nanoindentation measurements were carried out by means of multiple-partial-unloadingindentation on a Hysitron Triboindenter (Minneapolis, MN, USA). On each sample, 36 indentations in and 25 indentations next to the wear track were performed. The maximal load was $18 \mathrm{mN}$ and the hardness was evaluated at indentations of $15 \mathrm{~nm}$ and $80 \mathrm{~nm}$.

Static ToF-SIMS measurements for surface spectroscopy and imaging were performed using an ION-ToF IV instrument (ION-TOF GmbH, Münster, Germany). The primary ion gun was operated in the high current mode with $\mathrm{Bi}_{3}{ }^{+}$ions with an energy of $25 \mathrm{keV}$ and the emitted secondary ions were detected in negative polarity. Dynamic SIMS sputter depth profiling was carried out using a quadrupole SIMS system (SIMS 4550, Cameca, Gennevilliers, France) using $\mathrm{Cs}^{+}$primary ions with an energy of $5 \mathrm{kV}$.

The quantitative characterization of the surface chemistry was conducted by means of XPS (Axis Nova small spot X-Ray photoelectron spectrometer, Kratos Analytics Ltd., Manchester, UK) using a monochromatic $\mathrm{K} \alpha$-line of aluminum $(\mathrm{Al})$ at $1486.6 \mathrm{eV}$. The survey spectra were collected using a pass energy of $160 \mathrm{eV}$ and $10 \mathrm{eV}$ in the case of detail spectra. Charging effects were compensated by a self-balancing low electron energy neutralizer. The spot size of analysis was $350 \times 700 \mathrm{\mu m}^{2}$.

\section{Results and Discussion}

\subsection{Tribological Experiments}

\subsection{1. ta-C Lubricated by Ethylene Glycol}

The tribological behavior was studied with an SRV-tribometer. Figure 1 shows the characteristics of the coefficient of friction (COF). In general, the maximum of the COF over the oscillation period (breakaway) is given by the SRV-tribometer. In addition, the high-resolution signal gives an overview of the high COF during breakaway compared to the COF when the two bodies are in relative motion. No obvious wear of the coating was found. The area of running could be distinguished from the pristine area because of a slightly different contrast or light reflection behavior. Figure $1 \mathrm{a}, \mathrm{b}$ shows an experiment that was carried out with a lubricant temperature of $100{ }^{\circ} \mathrm{C}$. Initially, the COF was at about 0.1 . Within the first two hours of the experiment, the COF decreased to about 0.09 which can be explained by film smoothing. Then, the COF decreased abruptly within less than three minutes to about 0.02 where it remained for the rest of the experiment. A thermally activated process cannot be excluded because experiments at different temperatures showed an earlier decrease in the friction coefficient to 
ultra-low values for higher temperatures. In particular, in experiments performed at temperatures below $80^{\circ} \mathrm{C}$, no ultra-low friction regime was observed. Figure 1c shows the development of the $\mathrm{COF}$ at different temperatures between $60^{\circ} \mathrm{C}$ and $120^{\circ} \mathrm{C}$. The sudden reduction in friction could only be observed at elevated temperatures but not for $60^{\circ} \mathrm{C}$. At higher temperatures, the abrupt decrease in the COF occurred after shorter running time. At $120^{\circ} \mathrm{C}$, the system quickly ran dry because the lubricant vaporized (sudden increase in the COF at $6500 \mathrm{~s}$ ).
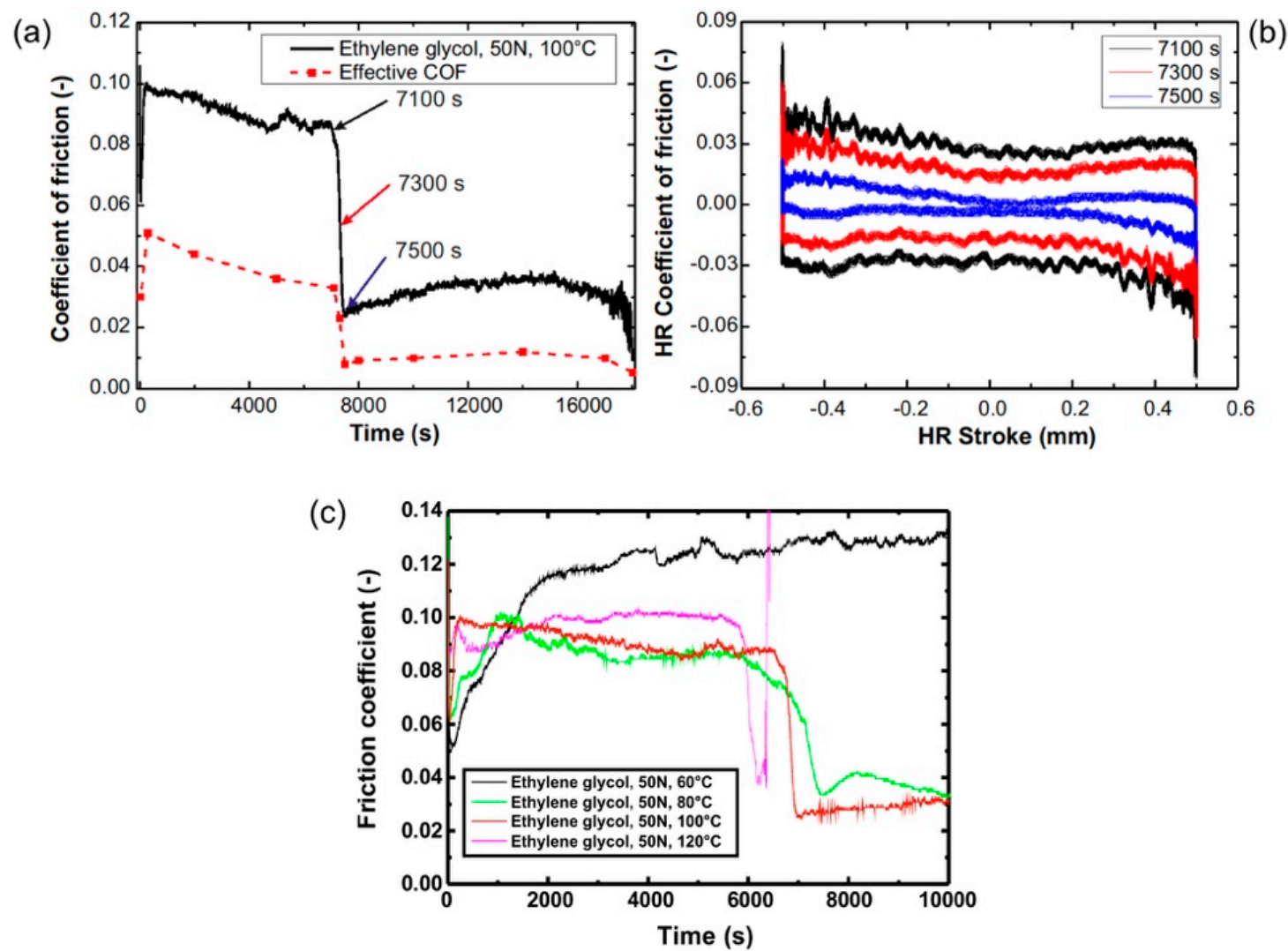

Figure 1. Friction of a ta-C/steel contact lubricated with ethylene glycol $\left(50 \mathrm{~N}, 100{ }^{\circ} \mathrm{C}\right)$. (a) SRV-coefficient of friction (COF) and effective COF for selected time periods as a function of time; (b) high-resolution COF against the high-resolution stroke. Data was taken for a time interval of $1 \mathrm{~s}$ at the time stamps $7100 \mathrm{~s}, 7300 \mathrm{~s}, 7500 \mathrm{~s}$, respectively; (c) friction coefficient measured at different temperatures between $60^{\circ} \mathrm{C}$ and $100{ }^{\circ} \mathrm{C}$.

For the experiment in Figure 1, we calculated the effective COF as the average over the entire friction cycle $\left(\mu_{e f f}=\sqrt{\frac{\int_{0}^{T} \mu^{2} d t}{T}}\right.$ ) for selected time intervals of one second of the experiment from the high-resolution COF-data which was recorded with a resolution of $40 \mu$ s. The use of an effective COF allows for a direct representation of the transferred friction power. The high-resolution COF plot in Figure $1 \mathrm{~b}$ shows the signal for three distinct time intervals recorded before, during, and immediately after the drop of friction coefficient. The high-resolution COF is plotted against the high-resolution position which shows the COF hysteresis. The COFs were higher during acceleration compared to the COFs when slowing down. The abrupt decrease in the friction coefficient was also observed in the effective COF. Based on these signals, we can conclude that not only did the COF during breakaway decrease, but rather the COF for the entire oscillation cycle was reduced in the ultra-low friction regime after the sudden decrease in the friction coefficient.

Initially, the relationship between the effective and the maximum COF was about 0.45 , which decreased to 0.35 during the experiment. This observation shows that the difference between 
the COFs at breakaway and during sliding was high especially due to the low viscosity of ethylene glycol. The effective COF after the abrupt decrease in the friction coefficient was in the super-lubricity regime (COFs below 0.01).

\subsubsection{Variation of the Tribological System}

To study the influence of the lubricant, the counter-body, and the running position, we repeated the experiment discussed above with modifications that were applied after the abrupt decrease in the ultra-low friction regime. In the first experiment, we exchanged the lubricant after $2.5 \mathrm{~h}$ running time. We cleaned the surface of the coating and the counter-body with acetone and isopropanol and added new ethylene glycol before restarting the experiment. The COF stayed at the ultra-low friction level that was achieved during running-in before as seen in Figure 2a. With this observation, we can exclude the possible degeneration of the lubricant as a reason for the sudden decrease in the friction coefficient.

(a)

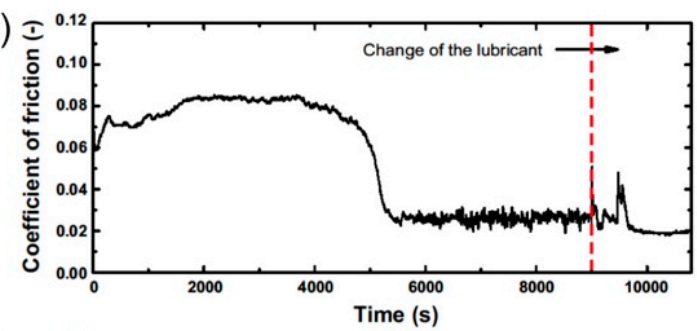

(c)

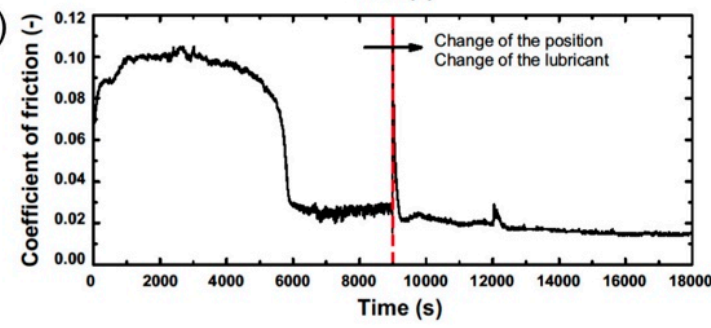

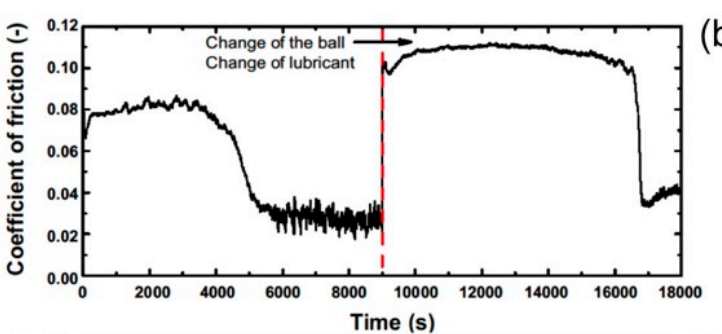

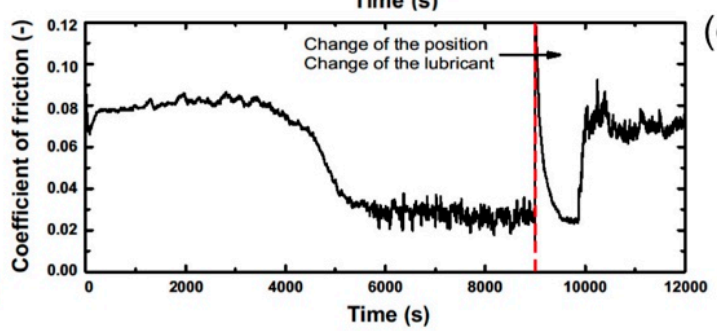

Figure 2. COF as a function of time for experiments with different changes in the tribosystem. Experiments were carried out after the first abrupt decrease in the friction coefficient (a) with a new lubricant; (b) with new counter-body and lubricant; and (c,d) at new running position and with new lubricant.

Figure $2 \mathrm{~b}$ shows data where the lubricant was replaced by new ethylene glycol and also the counter-body was substituted with a new one. Although the old wear track was reused, a complete new running-in was required to reach the low friction level again. In two further experiments, shown in Figure $2 c, d$, we changed the position on the coating and the lubricant and reused the counter-body. Figure $2 \mathrm{c}$ shows that at the beginning of the second experiment, only a very short running-in period was required before the $\mathrm{COF}$ again reached the ultra-low friction regime. In a control experiment the $\mathrm{COF}$ decreased again to the low friction regime after short running-in. However, when reaching the low level, the COF increased again, shown in Figure 2d, without producing visible wear of the coating.

The experiments in Figure 2c,d suggest that the counter-body has a significant influence on the tribological behavior of the system because when reusing the steel counter-body on pristine ta-C the coefficient of friction dropped within a few minutes. In the experiments of Figure $2 c, d$, the final pressure was $120 \mathrm{MPa}$ and $105 \mathrm{MPa}$, respectively. This indicates that a pressure reduction was not the only reason for the drop in the friction coefficient. The reason for the final increase in the COF in experiment of Figure $2 \mathrm{~d}$ was not clear but wear of adsorbed material seems to be likely.

Thus, one possible explanation for the observed sudden decrease in the COF after a long running-in is the formation of a transfer-layer on the counter-body. Directly after restart (after $9000 \mathrm{~s}$ ), the structure of the transfer-layer had to adapt to the surface structure of the coating which means that the low COF can be reached after the adaption process (Figure 2c). In the control experiment, shown 
in Figure 2d, the transfer-layer was most probably not thick enough for the adaption process, therefore the transfer-layer was removed during the new running-in. In the following sections, we further discuss chemical and physical properties of the ta- $\mathrm{C}$ coating and the steel counter-body with respect to further friction reducing mechanisms such as modification of the ta- $\mathrm{C}$ and adsorption of fragments of the lubricant.

\subsection{Surface Characterization}

\subsubsection{Wear of the Steel Counter-Body}

To better understand the origin of the ultra-low friction regime, the surfaces were analyzed with respect to morphology and chemistry. No damage to the coating itself was observed during or after the experiment. We evaluated the wear of the counter-body and measured the diameter of the contact area of the counter-body depending on the running time. Figure 3 shows the final contact diameter after running for a defined time. The contact pressure was estimated based on the load and the final diameter of the contact area. Comparing the development of the COF with the measured wear diameter of the counter-body no direct correlation between both parameters was observed. The ball showed ongoing wear until the contact pressure was reduced to 70-100 MPa where the diameter did not increase anymore. ToF-SIMS measurements revealed that the majority of the worn off particles were found outside of the wear track. We observed that wear did not stop after the strong decrease in the friction coefficient which suggests that there was no direct correlation between wear and the resulting reduced pressure with the friction coefficient in this experiment. Similarly Li et al. [23] analyzed the pressure dependence of friction in a sapphire-sapphire-contact where they observed that super-lubricity with water based lubricants can be achieved at a wide range of pressures owing to the low pressure-viscosity coefficient.

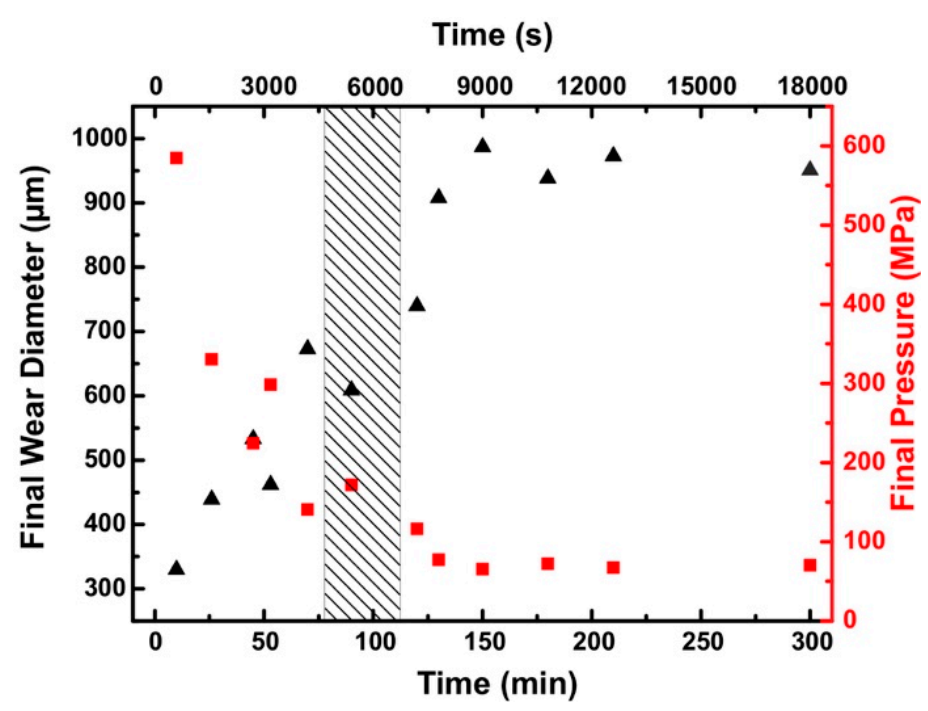

Figure 3. Final contact area of the counter-body (triangle) and the resulting final pressure (square) for different running times. The hatched area indicates the range of the typical running times when the sudden drop of the COF occurred.

\subsubsection{Roughness and Friction}

Figure 4 shows the surface roughness parameter $S_{a}$ (arithmetic average roughness) and the corresponding standard deviation based on data obtained with a confocal microscope. $S_{a}$ was within the range of $0.055 \pm 0.010 \mu \mathrm{m}$. Furthermore, $S_{q}$ (root mean squared roughness) was measured and was within the range of $0.075 \pm 0.010 \mu \mathrm{m}$ (not shown in Figure 4). Within the measurement accuracy, the roughness was measured with a confocal microscope and did not change. Thus, a possible 
systematic change of the surface roughness on this length scale can be excluded as a reason for the sudden reduction in the coefficient of friction.

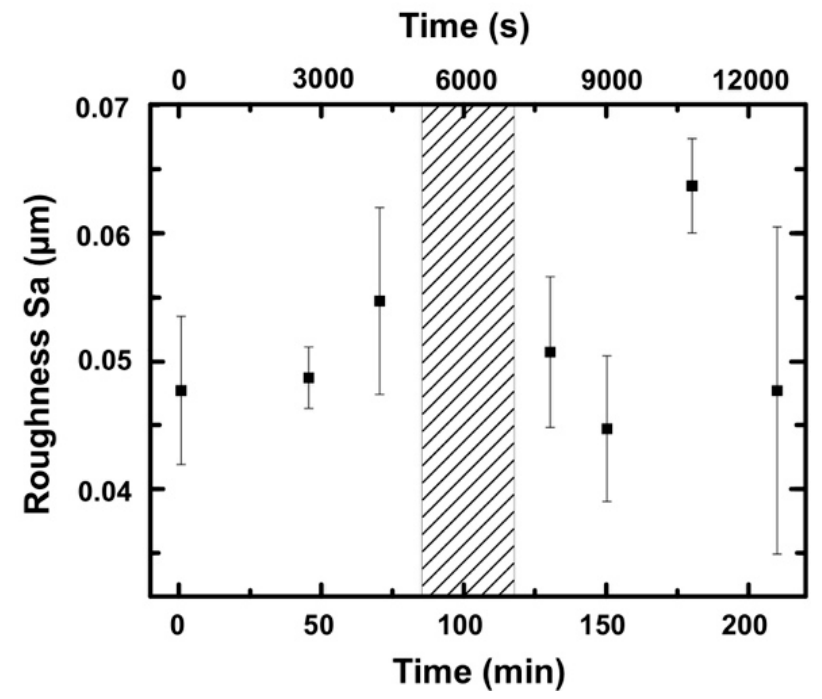

Figure 4. Surface roughness in the wear track after different times of running. The hatched area indicates the range of the typical running times when the abrupt decrease of the COF occurred.

In addition to the roughness measurements with a confocal microscope, the nano-scale roughness was determined with AFM. A typical topography image of a pristine ta-C coating is shown in Figure $5 \mathrm{a}$. Images were taken after running-in but before (Figure $5 b$ ) and after (Figure $5 c$ ) the abrupt decrease in the friction coefficient. On this length scale, grooves oriented in the sliding direction were detected after running-in. The roughness values as well as LFM COF values are shown in Figure 6. Data is shown for the entire image of $4 \times 4 \mu \mathrm{m}^{2}$ size and a smaller region of interest (ROI) of $1 \times 1 \mu \mathrm{m}^{2}$. The smaller ROI was selected to exclude obvious debris. The roughness values inside the wear-track were larger than on the pristine sample. There was an evident decrease of the nano-roughness after the decrease in the COF. A reason for the overall smaller LFM values observed for the surface after the macroscopic decrease in the COF may be the smoother surface. An initial surface roughening and a following smoothing process during the tribological experiment is a possible explanation for this. In addition, there might be a higher degree of hydrogen coverage on the surface. In simulations [24], the effective saturation of dangling bonds with hydrogen showed a reduction of the chemical reactivity of the carbon atoms. Hydrogen or hydroxyl groups chemisorbed to the surface of the ta-C coating and so can also contribute to the reduced adhesion between the coating and the tip and thus to the reduced friction.
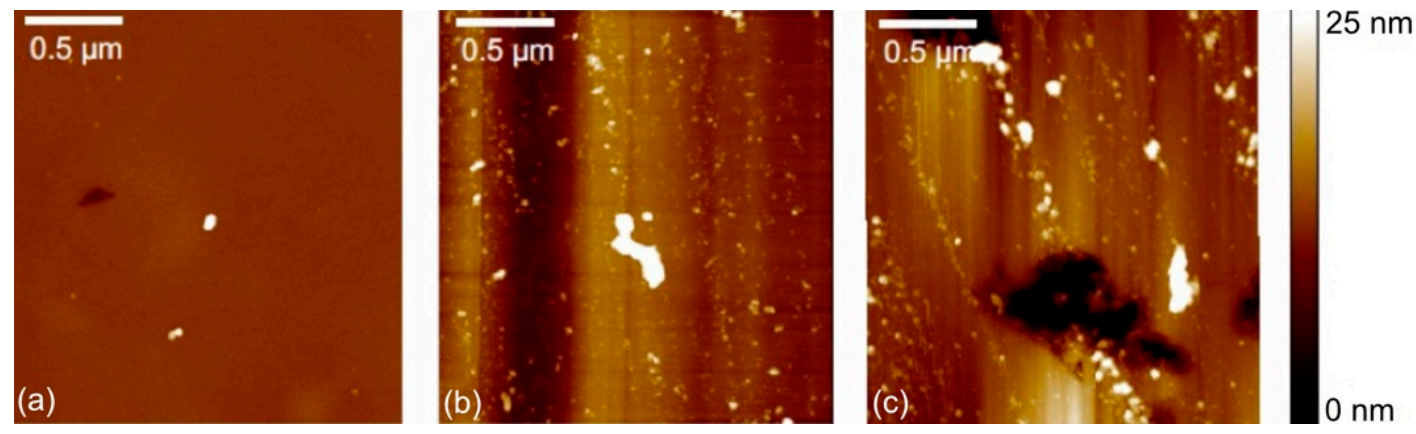

Figure 5. Topographic atomic force microscopy (AFM) images of the ta-C coating: (a) pristine surface prior to the experiment, (b) topography within the wear track prior to and (c) after the abrupt decrease of the friction coefficient. 

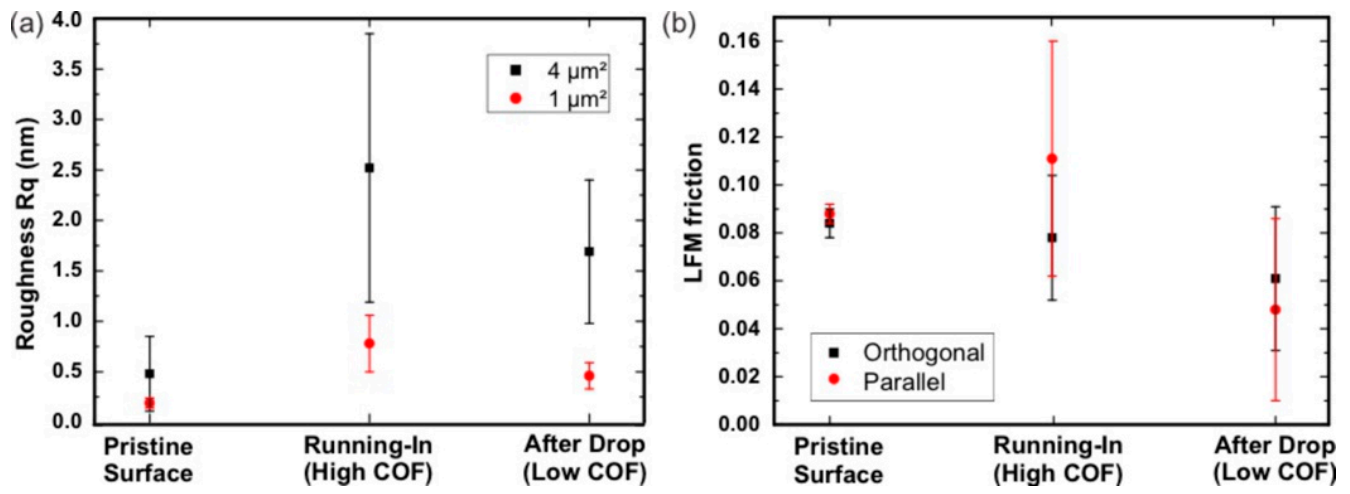

Figure 6. (a) Roughness and (b) friction values measured by means of atomic force microscopy. The friction values were measured parallel and perpendicular to the sliding direction in the wear tracks.

\subsubsection{Nano-Hardness}

The nano-hardness was measured in and next to the wear track before and after the decrease in the COF. For an indentation of 15-20 nm, the hardness was $35 \pm 4 \mathrm{GPa}$ which is lower when compared to the nano-hardness measured for an indentation between 70 and $80 \mathrm{~nm}$ where we measured a hardness of $60 \pm 5 \mathrm{GPa}$. The reduced hardness for the surface-near indentations can be caused by the roughness $[25,26]$. Furthermore, the effect of the bulk-structure cannot be neglected. Within the standard deviation, however, the measured values were the same for the pristine area as well as for the wear track prior to and after the decrease in the COF. The fact that the hardness values did not vary between the specimen allows us to conclude that even after the abrupt reduction in the COF, the amorphous carbon coating was structurally still intact within the first few hundred nanometers.

\subsubsection{ToF-SIMS Study of the ta-C Coating}

Four different wear tracks were analyzed in order to correlate the COFs with adsorbed species in the wear track as summarized in Table 1. The experiments were stopped twice before and after the abrupt decrease of the COF.

Table 1. Main characteristics of the experiments with deuterated ethylene glycol. Four wear tracks (P1-P4) were generated using four different counter-bodies (K1-K4).

\begin{tabular}{cccc}
\hline Wear Track/Ball & Running Time & Final COF & Deuterated Version \\
\hline P1/K1 & $12,000 \mathrm{~s}$ & 0.021 & $\mathrm{~d} 2$ \\
$\mathrm{P} 2 / \mathrm{K} 2$ & $3180 \mathrm{~s}$ & 0.090 & $\mathrm{~d} 2$ \\
$\mathrm{P} 3 / \mathrm{K} 3$ & $5400 \mathrm{~s}$ & 0.021 & $\mathrm{~d} 4$ \\
$\mathrm{P} 4 / \mathrm{K} 4$ & $1560 \mathrm{~s}$ & 0.076 & $\mathrm{~d} 4$ \\
\hline
\end{tabular}

Figure 7 shows ToF-SIMS mappings for the lateral distribution of selected characteristic fragments of different adsorbates in the wear tracks P1 to P4. These maps were collected in the so-called macro raster mode where small raster images $\left(400 \times 400 \mu \mathrm{m}^{2}\right)$ were combined to a large analysis area of $4 \times 4 \mathrm{~mm}^{2}$. In all analyzed wear tracks, deuterium-ions, and small molecular ions with deuterium in combination with oxygen and carbon were detected.

The peak at mass $2 \mathrm{amu}$ in the mass spectrum corresponds to deuterium. This signal was higher for the wear tracks lubricated with the ethylene glycol-d4 version (P3 and P4) compared to the $\mathrm{d} 2$ version (P1 and P2). Furthermore, the signal was higher for the wear tracks of the experiments stopped before the abrupt decrease in the COF ( $\mathrm{P} 2$ and $\mathrm{P} 4)$ compared to the corresponding experiments afterwards (Figure 8). The same correlation could be found for the OD-ions (18 amu). It cannot be excluded that deuterium was exchanged with hydrogen because the experiments were carried out at ambient room 
conditions which might explain the higher intensity ratios for the experiments P2 and P4 compared to P1 and P3. Therefore, the adsorption of deuterium, which can be referred as hydroxylation, seems to be a quick process since the intensities prior to the drop in friction coefficient were higher.

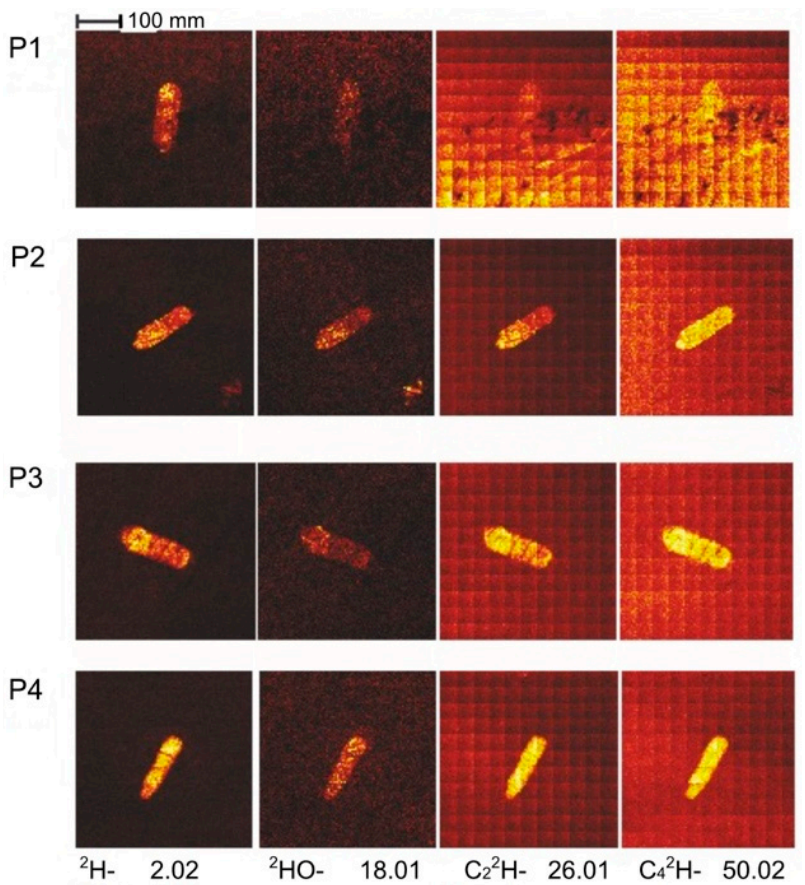

Figure 7. Time-of-flight secondary ion mass spectrometry (ToF-SIMS) mappings showing the lateral intensity distribution of selected ionic molecular fragments in the region of the wear tracks P1-P4.

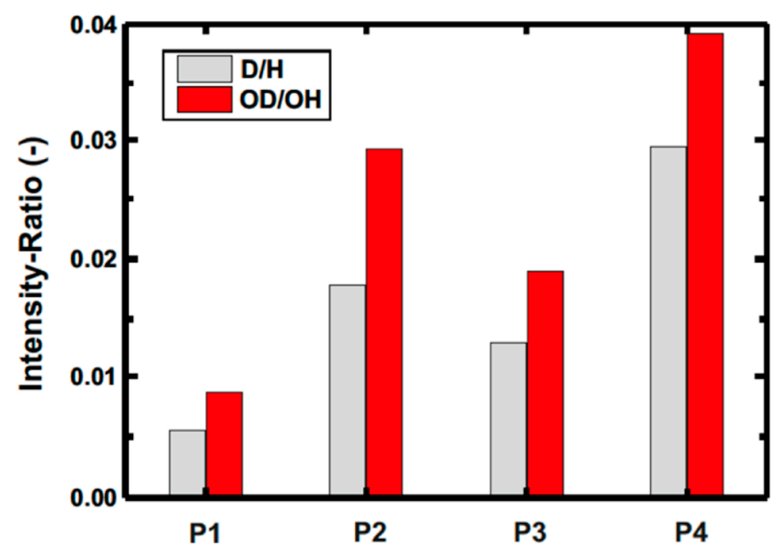

Figure 8. Intensity ratios based on ToF-SIMS-mass spectra considering a correction of $\mathrm{H} 2$ based on a pristine area of the sample.

We also analyzed the counter-bodies in the worn area by means of ToF-SIMS surface spectroscopy (Figure 9). No deuterium or deuterated hydroxyl-groups could be detected in the worn area. However, the intensity of oxygen was slightly higher in the contact area than in the surrounding area which may be due to the formation of iron oxide caused by the higher temperatures in the contact area. In general, friction processes result in higher local temperatures due to the contact of asperities [27]. This local heating might result in reactions of oxygen and water with iron [28]. These reactions in turn could have accelerated the oxidation in the worn part of the ball. The absence of deuterium in the worn area may be explained by an exchange of the deuterium in the lubricant with hydrogen from the water of the environmental humidity (Wu et al. [12]). 
K1

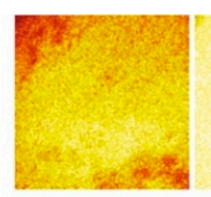

K2

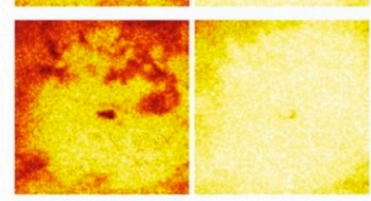

K3

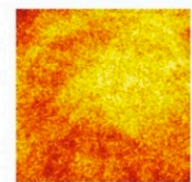

K4

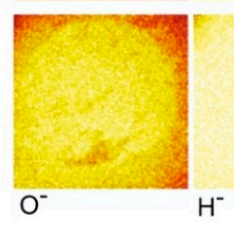

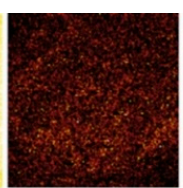
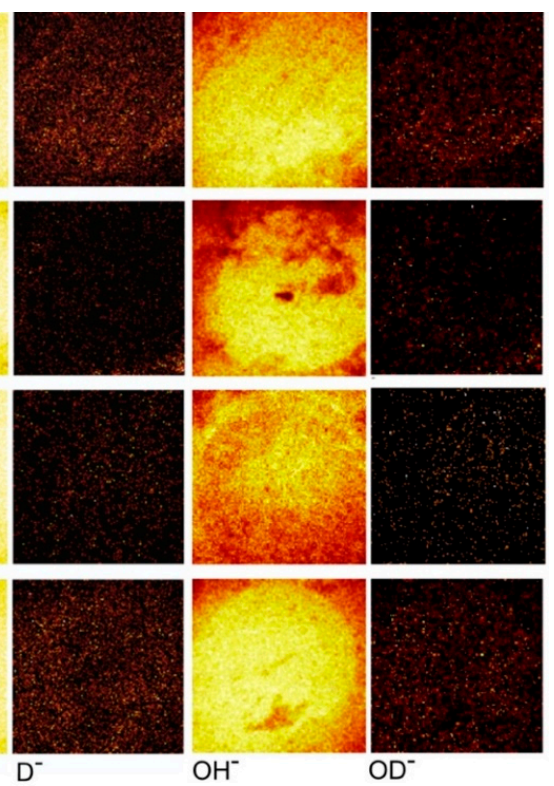

Figure 9. ToF-SIMS mappings of the counter-bodies after SRV measurement.

\subsubsection{SIMS Study of the ta-C Coating}

The depth resolved intensity-ratio of deuterium to carbon and oxygen to carbon measured on a pristine area of the sample for a sputter depth $<50 \mathrm{~nm}$ and inside the wear track before and after the abrupt decrease in the COF are shown in Figure 10. Here, the ${ }^{13} \mathrm{C}$-signal was used as reference because the ${ }^{12} \mathrm{C}$-signal was saturated. Also, the signals of the first $10 \mathrm{~nm}$ are shown in Figure 10 (left). Based on the intensity-ratios it is clear that more deuterium-containing fragments were adsorbed inside the wear tracks than outside. It should be noted that the ratio was higher for the measurement before the abrupt decrease in the COF as compared to the measurement afterwards, although the ratios inside the wear track were still higher at a depth of about $50 \mathrm{~nm}$ compared to the pristine area of the sample. Particularly, more deuterated species were detected in the wear track prior to the sudden decrease in the COF. More adsorbed molecules could be detected after the sudden decrease in the friction coefficient. One possible explanation for this observation is the competition between deuterium from the lubricant and protons from the environmental humidity which leads to a decreasing signal of deuterated fragments over time. Nevertheless, these SIMS-measurements indicate that adsorbates cannot explain the low coefficient of friction after the running-in period.

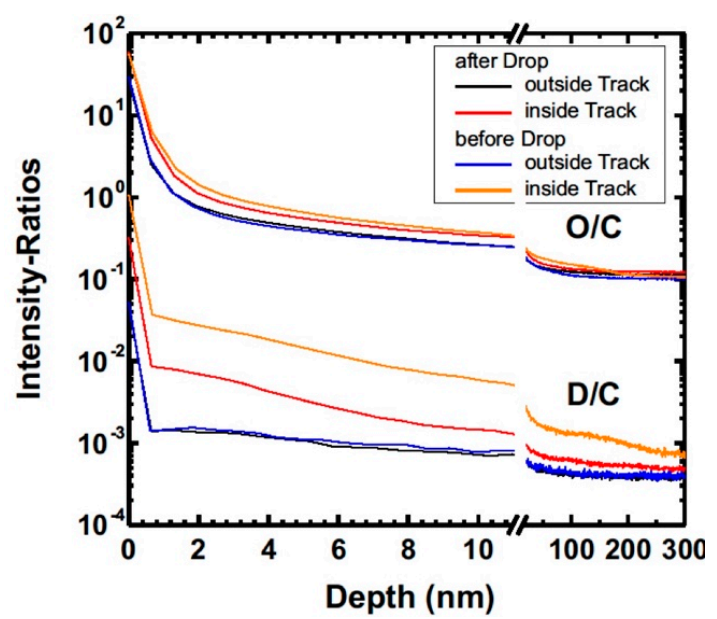

Figure 10. Intensity ratios of deuterium to carbon ${ }^{13} \mathrm{C}$ and oxygen to carbon ${ }^{13} \mathrm{C}$. 


\subsubsection{XPS Study of the Steel Counter-Body}

Because a low friction coefficient was observed after a short running-in period when the experiment was started with an already used counter-body, the counter-body seems to play a major role in enabling low COFs. In order to investigate the formation of a transfer-layer on the counter-body, XPS measurements were performed on cycle shaped wear tracks of the counter-bodies K1-K4 shown in Table 2.

Table 2. Detected peaks from peak shape analysis of X-ray photoelectron spectroscopy (XPS) core levels C1s and O1s $[29,30]$.

\begin{tabular}{ccc}
\hline Core Level & Energy (eV) & Corresponding Binding Structure \\
\hline $\mathrm{C} 1 \mathrm{~s}$ & 283.3 & $\mathrm{C}-\mathrm{Cr}$ \\
$\mathrm{C} 1 \mathrm{~s}$ & 285 & Carbon inside aliphatic hydrocarbons $\left(\mathrm{sp}^{3}\right)$ and DLC $\left(\mathrm{sp}^{3}\right)$ \\
$\mathrm{C} 1 \mathrm{~s}$ & 286.5 & Carbon with one oxygen as binding partner (alcohol, ether) $\left(\mathrm{sp}^{3}\right)$ \\
$\mathrm{C} 1 \mathrm{~s}$ & 288.7 & Carbon in carboxyl respectively carbonyl groups $\left(\mathrm{sp}^{3}\right)$ \\
\hline $\mathrm{O} 1 \mathrm{~s}$ & 530 & Oxygen in metal oxides \\
$\mathrm{O} 1 \mathrm{~s}$ & 531.6 & Oxygen in organics \\
\hline
\end{tabular}

Photoelectron lines of carbon, oxygen, and iron dominate the survey spectra, with some smaller contributions from contaminants such as silicon. The atomic concentrations of oxygen and carbon were calculated using standard sensitivity factors. The concentrations and the COFs are given in Figure 11. Neither the oxygen nor the carbon concentrations correlated with the observed friction levels. The oxygen concentration on the pristine steel ball initially decreased by about $10 \%$ and recovered before the abrupt reduction of the COF. After the abrupt decrease in the COF, the oxygen concentration was in the same range. The high oxygen concentration might indicate the presence of an oxide layer on the steel. Due to the short running time of the first experiment, this oxygen layer might have worn off and thus, less oxygen was detected. A longer running time could accelerate the formation of oxides, although it is not possible to distinguish the difference between storage (native oxygen) and the experiment. The carbon concentration initially increased. However, after a certain running time, a decreased concentration was observed.

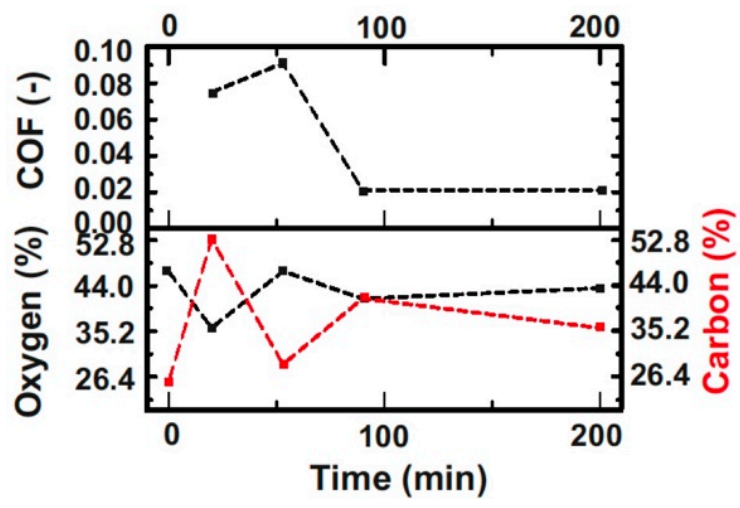

Figure 11. COF and calculated oxygen and carbon atomic concentrations obtained from the XPS spectra against time.

Chemical binding states of the prominent elements carbon and oxygen were analyzed by peak shape analysis of $\mathrm{C} 1 \mathrm{~s}$ and O1s detail spectra shown in Figure 12. For one ball, a pristine area was analyzed as reference. The XPS C1s and O1s core level detail spectra were normalized to an equal peak height of the maximum component. The atomic concentrations, as calculated from survey spectra 
and binding energies of the main components, are given inside the diagrams. The chemical states are summarized in Table 2.

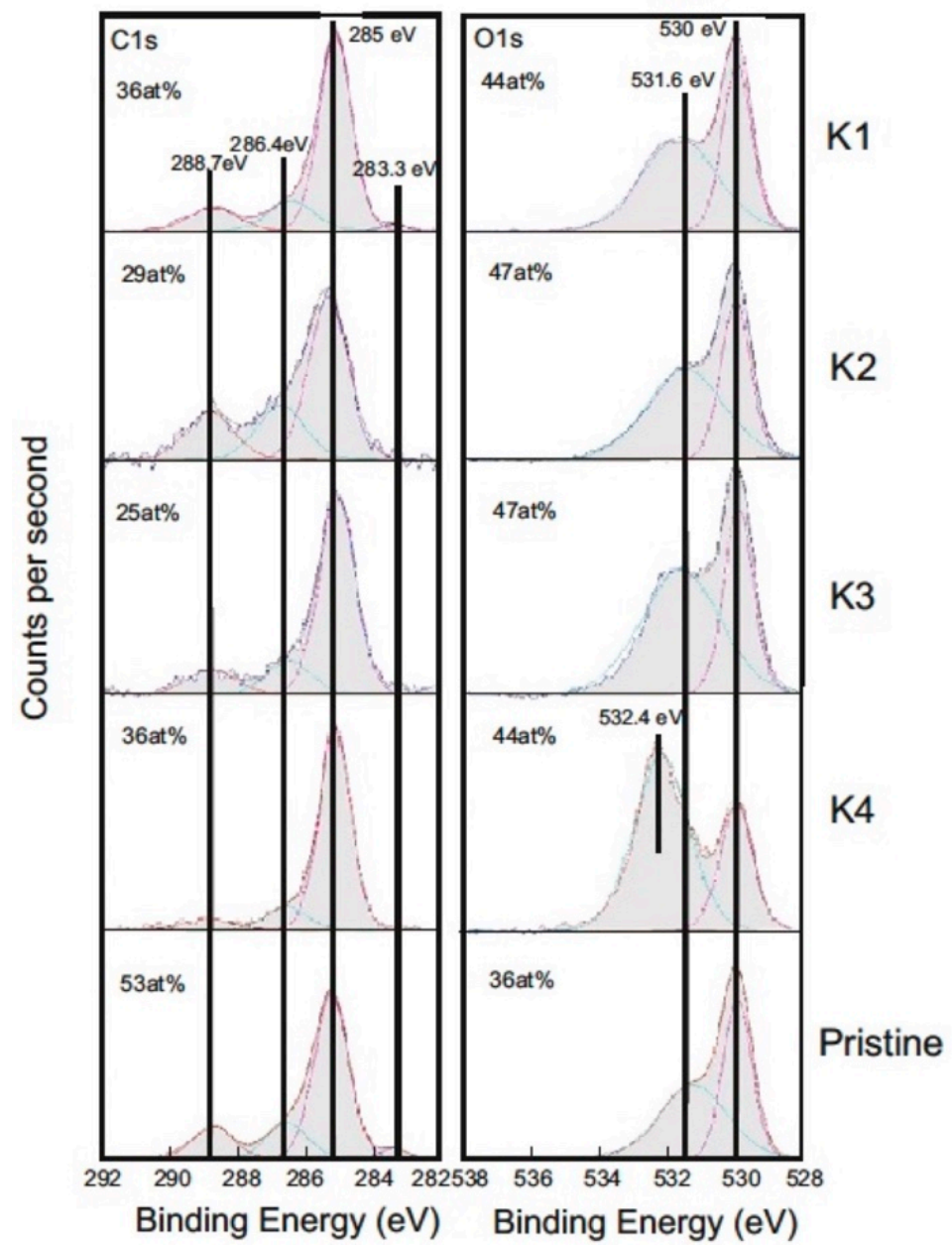

Figure 12. XPS $\mathrm{C} 1 \mathrm{~s}$ and $\mathrm{O} 1 \mathrm{~s}$ core level detail spectra. $\mathrm{K} 1-\mathrm{K} 4$ are the $100 \mathrm{Cr} 6$ steel counter-bodies (Table 2).

A $532.4 \mathrm{eV}$ line is typical for the alcohol group of ethylene glycol. In the common presence of alcohol, ether, carbonyl, and carboxyl groups, a broad and nearly symmetric structure around $532-533 \mathrm{eV}$ can be found. For the balls $\mathrm{K} 1$ and $\mathrm{K} 2$, no relevant change in investigated binding states was observed. The slightly higher contribution of carbon in an alcohol respectively ether group (C1s $286.5 \mathrm{eV}$ ) at the beginning of tribological loading (K2) may be attributed to the contribution of diethylene glycol, which decreased during tribological load. For the experiments with ethylene glycol-d4, the strongly increased O1s-peak at $532.4 \mathrm{eV}(\mathrm{K} 4)$ was caused by ethylene glycol residues. These were reduced during the tribological load (K3). Additionally, the contribution of oxygen bound in metal oxide increased during the tribological strain (oxidation of the surface).

\section{Discussion}

We investigated the tribological behavior of a ta-C/steel contact that was lubricated with ethylene glycol. An abrupt decrease in the coefficient of friction was observed after a longer running-in period of $95 \pm 15 \mathrm{~min}$ at elevated temperatures. To investigate the origin of this behavior, several influence parameters were analyzed such as surface roughness, counter-body wear, adsorbates, and transfer-layer formation. In summary, we observed that the micro- and nanoscale roughness and friction decreased during the running-in period. A substantial amount of deuterated fragments 
of lubricant was detected in the wear track before and after the decrease. However, the sudden macroscopic decrease in the COF cannot be explained by the nanoscale roughness or adsorbed fragments of the lubricant alone. In an experiment with a reused steel counter-body on a pristine ta-C surface, a much shorter (few minutes) running-in period to ultralow friction was observed for the second run of the ball. Together with the other results, this behavior indicates that the sudden decrease in the COF might correlate with a transfer-layer formation on the counter-body. We assume that similar to the tribochemical reactions of polyglycols [20] or glycerols [15] in DLC coated systems hydroxylation of the ta-C coating occurs. One can speculate that the hydroxylated coating together with tribodegraded ethylene glycol molecules (glycolic or formic acids) might then might play a role in driving the corrosion of the surface of the steel counter-body leading to the formation of a transfer layer. Molecular modelling together with reference experiments using ethylene glycol with a (small) but controlled water content will be necessary to support the hypothesis.

Author Contributions: Conceptualization, S.B., L.K. and R.W.S.; Formal analysis, S.B.; Funding acquisition, L.K. and R.M.; Investigation, S.B., M.S., R.M. and M.W.; Project administration, S.B., L.K. and R.W.S.; Resources, L.K., M.W. and R.W.S.; Supervision, R.W.S.; Validation, S.B.; Visualization, S.B.; Writing—original draft, S.B. and M.S.; Writing — review \& editing, R.W.S.

Funding: This work was funded by the Federal Ministry for Economic Affairs and Energy (BMWi) with the project Pegasus II (03ET1187A) and the German Research Foundation (DFG) for support within the CRC926 Microscale Morphology of Component Surfaces, subproject B08.

Acknowledgments: The authors thank Volker Weihnacht from the Fraunhofer Institute for Material and Beam Technology for providing the ta-C coatings, Wolfgang Bock (IFOS) for ToF-SIMS measurements, Kirstin I. Schiffmann from the Fraunhofer Institute for Surface Engineering and Thin Films for nanoindentation measurements. We acknowledge support by the German Research Foundation and the Open Access Publishing Fund of Technische Universität Darmstadt.

Conflicts of Interest: The authors declare no conflict of interest. The founding sponsors had no role in the design of the study; in the collection, analyses, or interpretation of data; in the writing of the manuscript, and in the decision to publish the results.

\section{References}

1. Hauert, R. An overview on the tribological behavior of diamond-like carbon in technical and medical applications. Tribol. Int. 2004, 37, 991-1003. [CrossRef]

2. Lawes, S.D.A.; Fitzpatrick, M.E.; Hainsworth, S.V. Evaluation of the tribological properties of DLC for engine applications. J. Phys. Appl. Phys. 2007, 40, 5427-5437. [CrossRef]

3. Zeng, A.; Neto, V.F.; Gracio, J.J.; Fan, Q.H. Diamond-like carbon (DLC) films as electrochemical electrodes. Diam. Relat. Mater. 2014, 43, 12-22. [CrossRef]

4. Grill, A. Diamond-like carbon: State of the art. Diam. Relat. Mater. 1999, 8, 428-434. [CrossRef]

5. Vetter, J. 60 years of DLC coatings: Historical highlights and technical review of cathodic arc processes to synthesize various DLC types, and their evolution for industrial applications. Surf. Coat. Technol. 2014, 257, 213-240. [CrossRef]

6. Logothetidis, S.; Kassavetis, S.; Charitidis, C.; Panayiotatos, Y.; Laskarakis, A. Nanoindentation studies of multilayer amorphous carbon films. Carbon 2004, 42, 1133-1136. [CrossRef]

7. Verein Deutscher Ingenieure. VDI 2840: Kohlenstoffschichten: Grundlagen, Schichttypen und Eigenschaften; Verein Deutscher Ingenieure: Düsseldorf, Germany, 2005.

8. Makowski, S.; Weihnacht, V.; Leson, A. Diesel-lubricated ta-C coatings. Lubr. Sci. 2013, 269-274. [CrossRef]

9. Vengudusamy, B.; Green, J.H.; Lamb, G.D.; Spikes, H.A. Tribology International Behaviour of MoDTC in DLC/DLC and DLC/steel contacts. Tribol. Int. 2012, 54, 68-76. [CrossRef]

10. De Barros Bouchet, I.M.; Martin, J.M.; Avila, J.; Kano, M.; Yoshida, K.; Bai, S.; Higuchi, Y.; Ozawa, N.; Kubo, M.; Asensio, M.C. Diamond-like carbon coating under oleic acid lubrication: Evidence for graphene oxide formation in superlow friction. Sci. Rep. 2017, 7, 46394. [CrossRef] [PubMed] 
11. Minami, I.; Kubo, T.; Nanao, H.; Mori, S.; Sagawa, T.; Okuda, S. Investigation of Tribo-Chemistry by Means of Stable Isotopic Tracers, Part 2: Lubrication Mechanism of Friction Modifiers on Diamond-Like Carbon Investigation of Tribo-Chemistry by Means of Stable Isotopic Tracers, Part 2: Lubrication Mechanism of Fri. Tribol. Trans. 2007, 37-41. [CrossRef]

12. Wu, X.; Ohana, T.; Tanaka, A.; Kubo, T. Tribochemical investigation of DLC coating in water using stable isotopic tracers. Appl. Surf. Sci. 2008, 254, 3397-3402. [CrossRef]

13. Ichiro, M.; Furesawa, T.; Kubo, T.; Nanao, H.; Mori, S. Investigation of tribo-chemistry by means of stable isotopic tracers: Mechanism for durability of monomolecular boundary film. Tribol. Int. 2008, 41, 1056-1062. [CrossRef]

14. Matta, C.; De Barros Bouchet, M.I.; Vachet, B.; Martin, J.M. Tribochemistry of tetrahedral hydrogen-free amorphous carbon coatings in the presence of $\mathrm{OH}$-containing lubricants. Lubr. Sci. 2008, 20, 137-149. [CrossRef]

15. Matta, C.; Joly-Pottuz, L.; De Barros Bouchet, M.I.; Martin, J.; Kano, M.; Zhang, Q.; Goddard, W. Superlubricity and tribochemistry of polyhydric alcohols. Phys. Rev. B 2008, 78, 085436. [CrossRef]

16. De Barros Bouchet, M.I.; Matta, C.; Le-Mogne, T.; Martin, J.M.; Zhang, Q.; Goddard, W.; Kano, M.; Mabuchi, Y.; Ye, J. Superlubricity mechanism of diamond-like carbon with glycerol. Coupling of experimental and simulation studies. J. Phys. Conf. Ser. 2007, 89, 012003. [CrossRef]

17. Kano, M.; Martin, J.M.; Yoshida, K.; De Barros Bouchet, M.I. Super-low friction of ta-C coating in presence of oleic acid. Friction 2014, 2, 156-163. [CrossRef]

18. Simic, R.; Kalin, M.; Kovac, J.; Jaksa, G. Adsorption of alcohols and fatty acids onto hydrogenated (a-C:H) DLC coatings. Appl. Surf. Sci. 2016, 363, 466-476. [CrossRef]

19. Erdemir, A.; Bindal, C.; Fenske, G.R.; Zuiker, C.; Wilbur, P. Characterization of Transfer Layers forming on Surfaces sliding against Diamond-Like Carbon. Surf. Coat. Technol. 1996, 86, 692-697. [CrossRef]

20. Scholz, C. Dirk Spaltmann, Matias Woydt, Friction Reduction on Powertrains by Polyglycols, Alternative Steels and/or Thin Films; STLE: Park Ridge, IL, USA, 2013; p. 1556885.

21. Scheibe, H.-J.; Leonhardt, M.; Leson, A.; Meyer, C.-F.; Stucky, T.; Weihnacht, V. Abscheidung superharter Kohlenstoffschichten mittels Laser-Arco auf dem Weg vom Labor in die industrielle Serienfertigung. Vak. Forsch. Prax. 2008, 20, 26-31. [CrossRef]

22. Varenberg, M.; Etsion, I.; Halperin, G. An improved wedge calibration method for lateral force in atomic force microscopy. Rev. Sci. Instrum. 2003, 74, 3362-3367. [CrossRef]

23. Li, J.; Zhang, C.; Luo, J. Investigation of the difference in liquid superlubricity between water- and oil-based lubricants. RSC Adv. 2015, 5, 63827-63833. [CrossRef]

24. Dai, L.; Sorkin, V.; Zhang, Y.-W. Effect of Surface Chemistry on the Mechanisms and Governing Laws of Friction and Wear. ACS Appl. Mater. Interfaces 2016. [CrossRef] [PubMed]

25. Bobji, M.S.; Biswas, S.K.; Pethica, J.B. Effect of roughness on the measurement of nanohardness-a computer simulation study. Appl. Phys. Lett. 1997, 71, 22-25. [CrossRef]

26. Bobji, M.S.; Biswas, S.K. Deconvolution of hardness from data obtained from nanoindentation of rough surfaces. J. Mater. Res. 1999, 14, 2259-2268. [CrossRef]

27. Liu, Y.; Erdemir, A.; Meletis, E.I. A study of the wear mechanism of diamond-like carbon films. Surf. Coat. Technol. 1996, 82, 48-56. [CrossRef]

28. Li, H.; Xu, T.; Wang, C.; Chen, J.; Zhou, H.; Liu, H. Friction behaviors of hydrogenated diamond-like carbon film in different environment sliding against steel ball. Appl. Surf. Sci. 2005, 249, 257-265. [CrossRef]

29. Jao, J.Y.; Han, S.; Chang, L.S.; Chen, Y.C.; Chang, C.L.; Shih, H.C. Formation and characterization of DLC:Cr:Cu multi-layers coating using cathodic arc evaporation. Diam. Relat. Mater. 2009, 18, 368-373. [CrossRef]

30. Moulder, J.F.; Chastain, J. Handbook of X-Ray Photoelectron Spectroscopy: A Reference Book of Standard Spectra for Identification and Interpretation of XPS Data; Physical Electronics: Eden Prairie, MN, USA, 1995.

(C) 2018 by the authors. Licensee MDPI, Basel, Switzerland. This article is an open access article distributed under the terms and conditions of the Creative Commons Attribution (CC BY) license (http:/ / creativecommons.org/licenses/by/4.0/). 